\title{
Biochemical and electrophoretic study for diagnosis of the disease stage in patients with asthmatic bronchitis
}

\author{
Wael M. Aboulthana ${ }^{1 *}$ (D), Marwa K. Darwish²,3, Mohab H. Halim', Hatim A. El-Baz ${ }^{1,4}$ and Osama S. Ahmed ${ }^{5}$
}

\begin{abstract}
Background: Asthmatic bronchitis is a chronic allergic airway disease diagnosed after development of chronic obstructive pulmonary disease symptoms. This study was designed to reveal relation of the different electrophoretic patterns to impairment of the lung functions in patients with asthmatic bronchitis.

Materials and methods: Patients were categorized into patients at mild stage $(n=10)$ and those at severe stage $(n=12)$ in comparison to healthy group $(n=21)$. The major blood components, arterial blood gases and electrolytes were immediately assayed in addition to assessment of liver enzymes and kidney functions. The pulmonary indices including forced expiratory volume in one second (FEV1), forced vital capacity (FVC), ratio of FEV1 to FVC and maximal expiratory pressure (MEP) were assayed. Furthermore, protein, lipid and calcium moieties of native protein patterns in addition to isoenzemes were electrophoretically detected.
\end{abstract}

Results: It was found that liver and kidney functions were significantly $(P<0.05)$ elevated in asthmatic bronchitis patients. $\mathrm{Ca}^{2+}$ is the only electrolyte that decreased significantly $(P<0.05)$ at the severe stage. Electrophoretic patterns showed that asthmatic bronchitis disease at mild and severe stages were physiologically similar to control by 54.5 and 75.6\% (protein), 73.1 and 41.6\% (lipid moiety), 66.4 and 30.6\% (calcium moiety), respectively. As regards to electrophoretic isoenzymes, the disease at mild and severe stages were similar to control by 95.2 and 35.4\% (catalase (CAT)), 40.1 and 50.5\% (peroxidase (POX)), 67.9 and 69.6\% (a-esterase (a-EST)), 83.1 and 73.1\% ( $\beta$-esterase $(\beta-E S T))$, respectively.

Conclusion: The native electrophoretic patterns used as diagnostic tool for determining the stage at which the patients with asthmatic bronchitis exist.

Keywords: Asthmatic Bronchitis, Pulmonary Indices, Electrophoresis, Native Patterns, Isoenzymes

\section{Introduction}

Asthmatic bronchitis is a chronic allergic airway disease involved by multiple cells (Nahori et al. 2001; Han et al. 2016). It may occur in a large number of patients who smoke cigarettes heavily. It is well known that the chronic mucous hypersecretion and airway hyperreactivity are considered as the most common features in the patients who suffer from this disease (Griffith and

\footnotetext{
* Correspondence: wmkamel83@hotmail.com

${ }^{1}$ Biochemistry Department, Genetic Engineering and Biotechnology Research

Division, National Research Centre, Dokki, Giza P.O. 12622 Egypt

Full list of author information is available at the end of the article
}

Garcia 1988). In addition, it is usually associated with major chronic-specific symptoms like cough and dyspnea (Molyneux et al. 2006; Yildiz and Igde 2018). It has become the most common chronic respiratory disease that may lead to mortality (Yadav and Mittal 2014).

The treatment with glucocorticoid inhalation is the most known and effective method that can suppress the rapid development of the disease and prevent asthma exacerbation but it is expressed as limited method due to the restricted knowledge of etiology about asthma whether the patients influenced by environment, exercise, mental state and other factors (Molyneux et al.,

\section{Springer Open}

(๑) The Author(s). 2020 Open Access This article is licensed under a Creative Commons Attribution 4.0 International License, which permits use, sharing, adaptation, distribution and reproduction in any medium or format, as long as you give appropriate credit to the original author(s) and the source, provide a link to the Creative Commons licence, and indicate if changes were made. The images or other third party material in this article are included in the article's Creative Commons licence, unless indicated otherwise in a credit line to the material. If material is not included in the article's Creative Commons licence and your intended use is not permitted by statutory regulation or exceeds the permitted use, you will need to obtain permission directly from the copyright holder. To view a copy of this licence, visit http://creativecommons.org/licenses/by/4.0/. 
2006; Blasi et al., 2013; Yadav and Mittal, 2014; Yildiz and Igde, 2018).

Asthma is associated with defined triggers of attacks such as viral infections, dusts, fumes and allergens in addition to a positive family history (Eden et al. 2006). Various factors involved in causation of the bronchial asthma and the clinical pathogenesis of this disease is not completely known. It might be related to immune, heredity, environment and other factors (Sherrill et al., 1999; Nahori et al., 2001). Therefore, a precision approach is necessary to integrate multiple dimensions (clinical, physiological, imaging and endotyping) to move the field forward in treatment of this disease (Segal and Martinez, 2018).

Asthmatic bronchitis is diagnosed after development of chronic obstructive pulmonary disease (COPD) symptoms. It occurs in $50 \%$ of patients with $\alpha$-antitrypsin deficiency (Eden, 2010). Also, it may occur alone before COPD development as a result of $\alpha$-antitrypsin deficiency (Sherrill et al., 1999; Eden et al., 2006; Eden 2010; Segal and Martinez, 2018). Early diagnosis is crucial and essential to prevent progression of the diseases and to implement preventive measures (Guarnieri, 2017).

The purpose of the present study is to explore simple and economically suitable tool for diagnosis of asthmatic bronchitis. The study revealed the physiological correlations among patients at mild and severe stages as compared to healthy individuals. Therefore, it was suggested that the disease might be detected sooner and diseasespecific interventions could be implemented.

\section{Materials and Methods}

\section{Patients and Methods}

Asthmatic bronchitis patients were diagnosed clinically in National Research Centre, Dokki, Giza, Egypt. The diagnosis was confirmed by biochemical indexes. Patients were categorized into patients at mild stage and severe stage based on history and clinical data sheets in addition to the imaging examination. Patients who met clinical diagnostic criteria for asthmatic bronchitis and revised by the subspecialty group of respiratory diseases and approved to obey this diagnostic study were selected according to specific inclusion criteria to be under the current study.

\section{Inclusion Criteria}

All patients had symptoms of airflow limitation and fulfilled lung function criteria as set out by the National Heart and Lung Institute/World Health Organization Global Initiative for Asthma guidelines (GINA, 2017) had FEV1/FVC of less than $80 \%$ and substantial improvement in FEV1 $>200 \mathrm{ml}$ or $12 \%$ of the base line value $15 \mathrm{~min}$ after taking $200-400 \mu$ g, i.e., $2-4$ puffs from a standard metered dose inhaler of nebulized salbutamol and or diurnal variation in PEF $>20 \%$.

\section{Exclusion Criteria}

1. Recent hospitalization or discharge from a hospital due to exacerbation of asthma.

2. COPD patients.

3. Chronic debilitating disorders as; renal disease, diabetes, hypertension, cardiac disease, diarrhea, alcohol abuse, and/or malignancy.

4. Patients on diuretics.

5. Currently pregnant females.

6. Patient known to have any thyroid dysfunctions.

The specimens (fasting venous blood) were drawn from control (healthy individuals) (21 sample), asthmatic bronchitis patients at mild stage (10 sample) and severe stage (12 sample) then placed into separation gel tube and Ethylene Diamine Tetraacetic Acid-2K (EDTA-2K) anticoagulation tube with each $2 \mathrm{ml}$ tube. Another blood samples were collected and centrifuged at $1500 \mathrm{rpm}$ for 15 min and the clear serum transferred into new eppendorff then stored at $-20{ }^{\circ} \mathrm{C}$ until used.

\section{Major Blood Components}

Arterial blood samples were collected with heparinized syringes and immediately analyzed using automated blood gas analyzer (ABL 725, Radiometer Medical ApS, Copenhagen, Denmark) for measuring the blood gases $\left(\mathrm{PH}, \mathrm{PCO}_{2}, \mathrm{PO}_{2}, \mathrm{SO}_{2}\right.$ and $\left.\mathrm{HCO}_{3}{ }^{-}\right)$and the electrolytes $\left(\mathrm{Na}^{+}\right.$and $\left.\mathrm{K}^{+}\right)$at $37^{\circ} \mathrm{C}$. Levels of hemoglobin (HB), white blood cells (WBCs) and platelets (PLT) were quantified in whole blood samples by an automatic blood analyzer (XE 2100 D; Sysmex, Kobe, Japan). The other electrolytes $\left(\mathrm{Ca}^{2+}, \mathrm{Mg}^{2+}\right.$ and $\left.\mathrm{P}^{3+}\right)$ were assayed in serum samples using fully automated system.

\section{Liver and Kidney Functions}

Activities of liver enzymes (alanine aminotransferase (ALT) and aspartate aminotransferase (AST)) were assessed kinetically in serum samples. Moreover, levels of urea and creatinin (creat.) were determined using commercially available kits purchased from SPINREACT (Santa Coloma, Spain).

\section{Pulmonary Functions}

The lung functions including forced expiratory volume in one second (FEV1), forced vital capacity (FVC), ratio of FEV1 to FVC and maximal expiratory pressure (MEP) were assayed in asthmatic bronchitis patients at mild and severe stages before and after receiving treatment using a spirometry (Spirosift spirometry 5000 FUKUDa 
NENSHI) according to method suggested by Freire et al. (2008) and modified by Blasi et al. (2013).

\section{Ethical Considerations}

All procedures performed in studies involving human participants were in accordance with the ethical standards of Institutional Human Ethical Committee of National Research Centre, Dokki, Giza, Egypt, and with the 1964 Helsinki Declaration and its later amendments or comparable ethical standards.

\section{Statistical Analysis}

Data were expressed as mean \pm standard error (SE) of studied groups using one-way analysis of variance (oneway ANOVA) followed by Bonferroni test. Analysis was carried out by Statistical Package for Social Sciences (SPSS for windows, version 11.0). Values of $P<0.05$ regards as significant. Moreover, the statistical positive and negative correlations were evaluated among all determined parameters. Values of $P<0.05$ were considered significant correlation and those of $\mathrm{P}<0.01$ were considered highly significant one.

\section{Electrophoretic Protein Patterns}

Total protein concentration was determined in the serum samples containing water soluble proteins using bovine serum albumin as standard according to method suggested by Bradford (1976). Concentration of total protein should be equal in all wells.

The native proteins were separated electrophoretically through Polyacrylamide Gel Electrophoresis (PAGE) according to the methods described by Hames (1990) and modified recently by Darwesh et al. (2015) who reported that samples, gels and running buffers were lacking sodium dodecyl sulphate. The native bands were stained by Commassie Brilliant Blue G-250 for visualizing protein bands. The relative mobility (Rf) and band percent (B\%) of the electrophoretically separated proteins were determined in addition to the molecular weights (Mwts) which were estimated in comparison to marker of standard molecular weights with regularly spaced bands ranging from 6.458 to $195.755 \mathrm{KDa}$. Furthermore, the lipid and calcium moieties of the native proteins were stained by mean of isoelectrophoresis. The lipid moiety was stained by Sudan Black B (SBB) (Subramaniam and Chaubal 1990). In addition, calcium moiety was stained according to method suggested by Abulyazid et al. (2017) and Abd Elhalim et al. (2017) using Alizarin Red 'S' prepared according method described by Zacharia and Kakati (2004).

\section{Electrophoretic Isoenzymes}

Native polyacrylamide gel was stained for detecting the isoenzymes electrophoretically after electrophoretic run.
For catalase (CAT) and peroxidase (POX) patterns, the gels were stained based on methods suggested by Siciliano and Shaw (1976) and Rescigno et al. (1997), respectively.

Furthermore, for detecting in-gel $\alpha$ - and $\beta$-esterase (EST) patterns, native gel was incubated in reaction mixture containing $\alpha, \beta$-naphthyl acetate $\left(5.58 \times 10^{-3} \mathrm{mM}\right.$, $\mathrm{pH}$ 7.5) as substrates along with dye coupler Fast Blue RR based on the method modified recently by Ahmad et al. (2012).

\section{Data Analysis}

The polyacrylamide gel plates were photographed by gel documentation system then analyzed using Quantity One software (Version 4.6.2). The Rf and B\% of the electrophoretically separated bands were determined by this program. In addition, the similarity index (SI\%) was calculated to compare the physiological state of the asthmatic bronchitis patients at mild and severe stages with respect to control group.

\section{Results}

As illustrated in Table 1, no statistical differences was noticed in the major blood components (HB, WBCs and PLT) in asthmatic bronchitis patients at mild and severe stages when compared to healthy individuals.

Liver enzymes (ALT and AST) were significantly $(P<$ 0.05 ) elevated in asthmatic bronchitis patients at mild and severe stages with respect to control. No differences were noticed statistically between asthmatic bronchitis patients at mild and severe stages. As regards to kidney functions (urea and creat.), it was found that urea was significantly $(P<0.05)$ elevated in patients at mild and severe stages when compared to control individuals. No statistically differences were noticed in creat. level between asthmatic bronchitis patients at both stages with respect to control.

In addition, the blood gases showed no differences recorded significantly in asthmatic bronchitis patients at both of mild and severe stages when compared to healthy individuals. Furthermore, no statistical variations were noticed in most of the electrolytes $\left(\mathrm{Na}^{+}, \mathrm{K}^{+}, \mathrm{Mg}^{2+}\right.$ and $\mathrm{P}^{3+}$ ) when compared to healthy individuals. It was found that $\mathrm{Ca}^{2+}$ level decreased significantly $(P<0.05)$ in asthmatic bronchitis patients at severe stage when compared to healthy individuals and to patients at mild stage.

The pulmonary functions were not affected before or after receiving treatment in asthmatic bronchitis patients at mild and severe stages. As revealed in Table 2, it was found that all pulmonary functions declined significantly $(P<0.05)$ in patients at mild and severe stages when compared to healthy individuals. No statistical difference was observed in those functions when patients at mild stage compared to that at severe stage. 
Table 1 Statistical significance of major blood components (hemoglobin (HB), white blood cells (WBCs) and platelets (PLT)), liver and kidney functions, blood gases and electrolytes showing the differences between asthmatic bronchitis patients at mild and severe stages as compared to control

\begin{tabular}{|c|c|c|c|c|}
\hline & & \multirow[t]{2}{*}{ Control } & \multicolumn{2}{|c|}{ Asthmatic Bronchitis Patients } \\
\hline & & & Mild & Severe \\
\hline HB & & $12.63 \pm 0.23$ & $12.72 \pm 0.45$ & $12.68 \pm 0.27$ \\
\hline WBCs & & $5.92 \pm 0.31$ & $6.02 \pm 0.66$ & $7.09 \pm 0.51$ \\
\hline PLT & & $256.48 \pm 10.98$ & $256.70 \pm 31.74$ & $231.00 \pm 18.17$ \\
\hline \multirow[t]{2}{*}{ Liver Functions } & $\mathrm{ALT}$ & $12.48 \pm 0.39$ & $14.50 \pm 0.56^{\mathrm{a}}$ & $15.17 \pm 0.83^{\mathrm{a}}$ \\
\hline & AST & $15.00 \pm 0.49$ & $17.50 \pm 0.72^{\mathrm{a}}$ & $18.00 \pm 0.97^{\mathrm{a}}$ \\
\hline \multirow[t]{2}{*}{ Kidney Functions } & Urea & $20.05 \pm 0.66$ & $23.50 \pm 0.60^{a}$ & $24.75 \pm 0.78^{\mathrm{a}}$ \\
\hline & Creat. & $0.86 \pm 0.02$ & $0.79 \pm 0.03$ & $0.81 \pm 0.06$ \\
\hline \multirow[t]{5}{*}{ Blood Gases } & $\mathrm{PH}$ & $7.39 \pm 0.01$ & $7.39 \pm 0.01$ & $7.38 \pm 0.01$ \\
\hline & $\mathrm{PCO}_{2}$ & $34.34 \pm 2.28$ & $36.29 \pm 0.96$ & $38.58 \pm 1.00$ \\
\hline & $\mathrm{PO}_{2}$ & $81.52 \pm 0.75$ & $80.60 \pm 1.07$ & $83.29 \pm 1.64$ \\
\hline & $\mathrm{SO}_{2}$ & $0.97 \pm 0.002$ & $0.97 \pm 0.002$ & $0.96 \pm 0.003$ \\
\hline & $\mathrm{HCO}_{3}^{-}$ & $22.24 \pm 0.60$ & $23.66 \pm 0.69$ & $23.91 \pm 0.60$ \\
\hline \multirow[t]{5}{*}{ Electrolytes } & $\mathrm{Na}^{+}$ & $136.38 \pm 4.64$ & $138.40 \pm 0.58$ & $141.25 \pm 1.02$ \\
\hline & $\mathrm{K}^{+}$ & $4.20 \pm 0.11$ & $4.06 \pm 0.09$ & $4.23 \pm 0.23$ \\
\hline & $\mathrm{Ca}^{2+}$ & $9.00 \pm 0.11$ & $9.14 \pm 0.24$ & $7.75 \pm 0.43^{\mathrm{ab}}$ \\
\hline & $\mathrm{Mg}^{2+}$ & $2.03 \pm 0.02$ & $1.99 \pm 0.09$ & $1.92 \pm 0.08$ \\
\hline & $\mathrm{P}^{3+}$ & $3.33 \pm 0.10$ & $2.84 \pm 0.15$ & $3.13 \pm 0.45$ \\
\hline
\end{tabular}

As revealed in Fig. 1a, it was noticed that there are 8 types of native proteins identified at Rfs ranged from 0.046 (Mwt 214.04 KDa) to 0.954 (Mwts 6.64 KDa) in sera of the healthy individuals. Five common protein bands were identified at Rfs 0.232, 0.406, 0.493, 0.804 and 0.954 (Mwts 83.862, 35.392, 25.123, 11.124 and 6.637 KDa, respectively). No characteristic protein bands were observed.

Table 2 Statistical significance of serum pulmonary functions before and after receiving treatment showing the differences between asthmatic bronchitis patients at mild and severe stages as compared to control

\begin{tabular}{lllll}
\hline & & Control & \multicolumn{2}{l}{ Asthmatic bronchitis patients } \\
\cline { 3 - 5 } & & & Mild & Severe \\
\hline Pre-treatment & FEV1 & $0.95 \pm 0.004$ & $0.62 \pm 0.03^{\mathrm{a}}$ & $0.62 \pm 0.04^{\mathrm{b}}$ \\
& FVC & $0.92 \pm 0.003$ & $0.81 \pm 0.04^{\mathrm{a}}$ & $0.75 \pm 0.03^{\mathrm{a}}$ \\
& FEV1/FVC\% & $0.85 \pm 0.004$ & $0.70 \pm 0.02^{\mathrm{a}}$ & $0.68 \pm 0.04^{\mathrm{a}}$ \\
& MEF25-75 & $1.10 \pm 0.02$ & $0.33 \pm 0.04^{\mathrm{a}}$ & $0.30 \pm 0.04^{\mathrm{a}}$ \\
Post-treatment & FEV1 & $1.11 \pm 0.01$ & $0.75 \pm 0.04^{\mathrm{a}}$ & $0.74 \pm 0.04^{\mathrm{a}}$ \\
& FVC & $1.11 \pm 0.01$ & $0.89 \pm 0.04^{\mathrm{a}}$ & $0.82 \pm 0.03^{\mathrm{a}}$ \\
& FEV1/FVC\% & $0.97 \pm 0.003$ & $0.84 \pm 0.02^{\mathrm{a}}$ & $0.82 \pm 0.04^{\mathrm{a}}$ \\
& MEF25-75 & $1.28 \pm 0.02$ & $0.43 \pm 0.05^{\mathrm{a}}$ & $0.41 \pm 0.05^{\mathrm{a}}$ \\
\hline
\end{tabular}

Values are expressed as mean \pm SE. ${ }^{a}$ Significant difference as compared to control $(P<0.05)$, 'bignificant difference as compared to patients at mild stage $(P<0.05)$
In patients at mild stage, it was found that 3 normal protein bands were disappeared with existence of 2 abnormal ones (Rfs 0.073 and 0.123; Mwts 188.705 and 148.11 KDa, respectively). In patients at severe stage, the $2^{\text {nd }}$ and $3^{\text {rd }}$ normal proteins were shifted to be identified at Rfs 0.077 and 0.125 (Mwts 185.083 and 146.683, respectively).

From the dendogram and calculations of the SI\%, it was found that number and arrangement of the protein bands in the disease at mild stage is physiologically similar to control by $54.5 \%$. Moreover, the disease at severe stage is similar to control by $75.6 \%$. In addition, the patients at mild and severe stages are physiologically similar by $77 \%$.

As presented graphically in Fig. 1b, it was found that 12 common lipid moiety of protein bands were identified at Rfs ranged from 0.061 to 0.958 and $\mathrm{B} \%$ from 0 to 12.939 in sera of the healthy individuals. There is only one characteristic band noticed in asthmatic bronchitis patients at severe stage at Rf 0.035 (B\% 14.109).

No normal bands disappeared in asthmatic bronchitis patients at both mild and severe stages but 2 abnormal bands were identified at mild stage at Rfs 0.179 and 0.496 (B \% 8.231 and 5.457, respectively). At the severe stage, 2 abnormal bands were identified at Rfs 0.179 and 


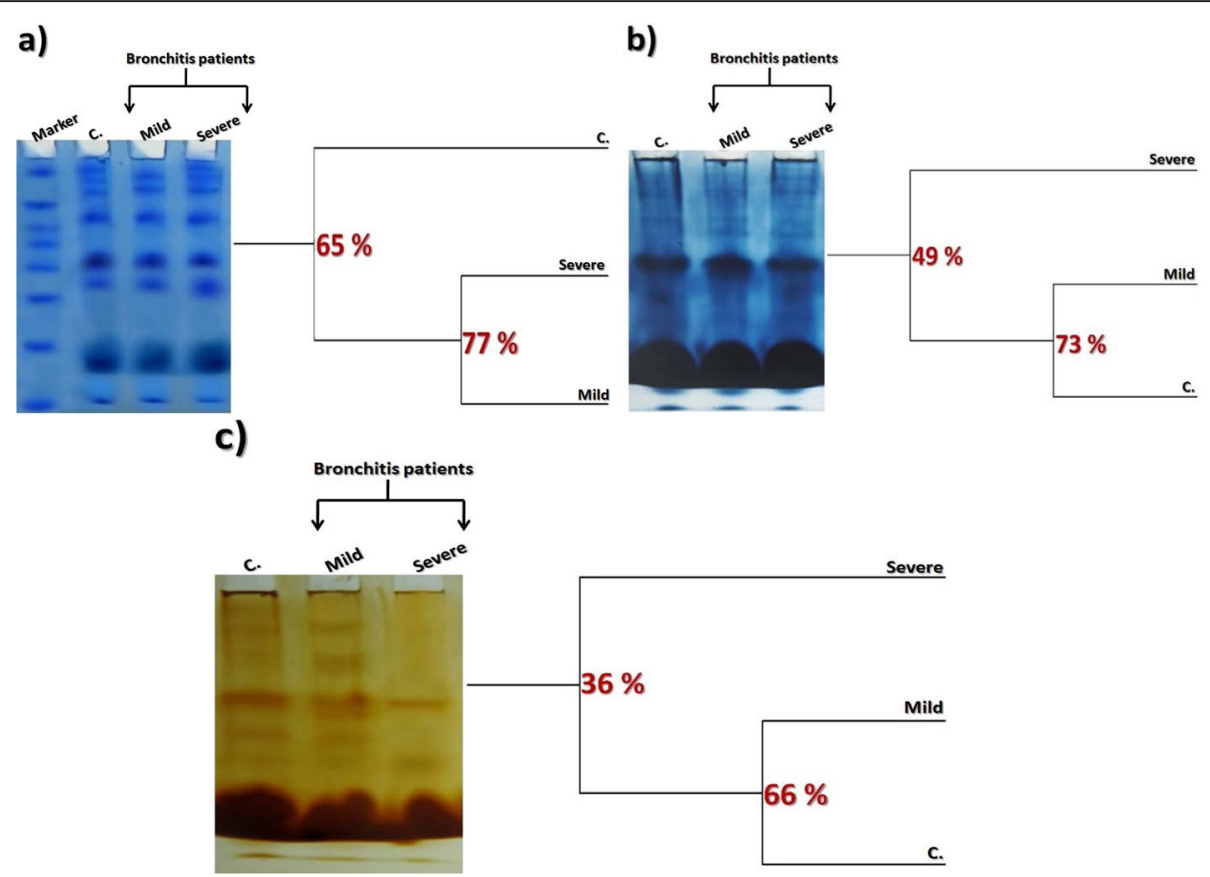

Fig. 1 Electrophoretic native patterns showing the physiological variations in bands number, arrangement and similarity percent (SI\%) in a) protein, $\mathbf{b}$ ) lipid moiety of native protein, and $\mathbf{c}$ ) calcium moiety of native protein in asthmatic bronchitis patients at mild and severe stages as compared to control

0.497 (B\% 10.084 and 2.133, respectively) in addition to the characteristic one (Rf 0.035 and B\% 14.109).

From dendogram and calculated SI\% values, it was found that number and arrangement of bands of lipid moiety at the mild stage is similar to those of control by $73.1 \%$. Moreover, the disease at severe stage is physiologically similar to control by $41.6 \%$. Furthermore, the mild and severe stages of the disease are physiologically similar by $55.8 \%$.

Data illustrated graphically in Fig. 1c showed that 4 common calcium moiety of protein bands were identified at Rfs 0.392, 0.616, 0.845 and 0.954 (B\% 12.870, 11.757, 17.736, and 9.690, respectively) in sera of control group. Two characteristic bands were identified in patients at mild stage at Rfs 0.263 and 0.444 (B\% 12.234 and 12.444, respectively) with hiding 2 normal bands. As regards to patients at severe stage, it was observed that 4 normal calcium moiety bands were completely disappeared without existence of abnormal ones.

The dendogram and calculated SI\% values stated that number and arrangement of bands of calcium moiety in the disease at the mild stage is similar to those of control by $66.4 \%$. Moreover, the disease at severe stage is physiologically similar to control by $30.6 \%$. Moreover, the mild and severe stages of the disease are physiologically similar by $41.5 \%$.

As presented graphically in Fig. 2a, it was found that no statistical variations among all groups in intensity of protein bands. As regards to intensities of lipid and calcium moieties of native proteins, it was noticed that intensities of the lipid and calcium moieties were significantly $(P<0.05)$ lowered in asthmatic bronchitis patients at both stages when compared to healthy individuals. Moreover, intensities of that moieties decreased significantly $(P<0.05)$ in patients at severe stages when compared to the mild stage.

As regards to quantities of the native bands (Fig. 2b), it was found that quantities of protein bands decreased significantly $(P<0.05)$ in patients at mild and severe stages when compared to healthy individuals. With respect to patients at mild stage, quantities of the protein bands lowered significantly $(P<0.05)$ in patients at severe stage. As regards to quantities of the lipid and calcium moieties of native protein, it was noticed that quantities of the lipid and calcium moieties were significantly $(P<0.05)$ elevated in asthmatic bronchitis patients at severe stage when compared to the patients at mild stage.

Data illustrated in Fig. 3a, it was noticed that CAT isoenzyme was expressed by 4 normal types which are considered as common types identified at Rfs 0.247, 0.366, 0.755 and 0.962 (B\% 22.83, 22.97, 33.40 and 20.80, respectively). No normal bands disappeared in patients at both mild and severe stages but only one characteristic CAT type was identified at $0.146(\mathrm{~B} \% 17.20)$ in patients at severe stage. 

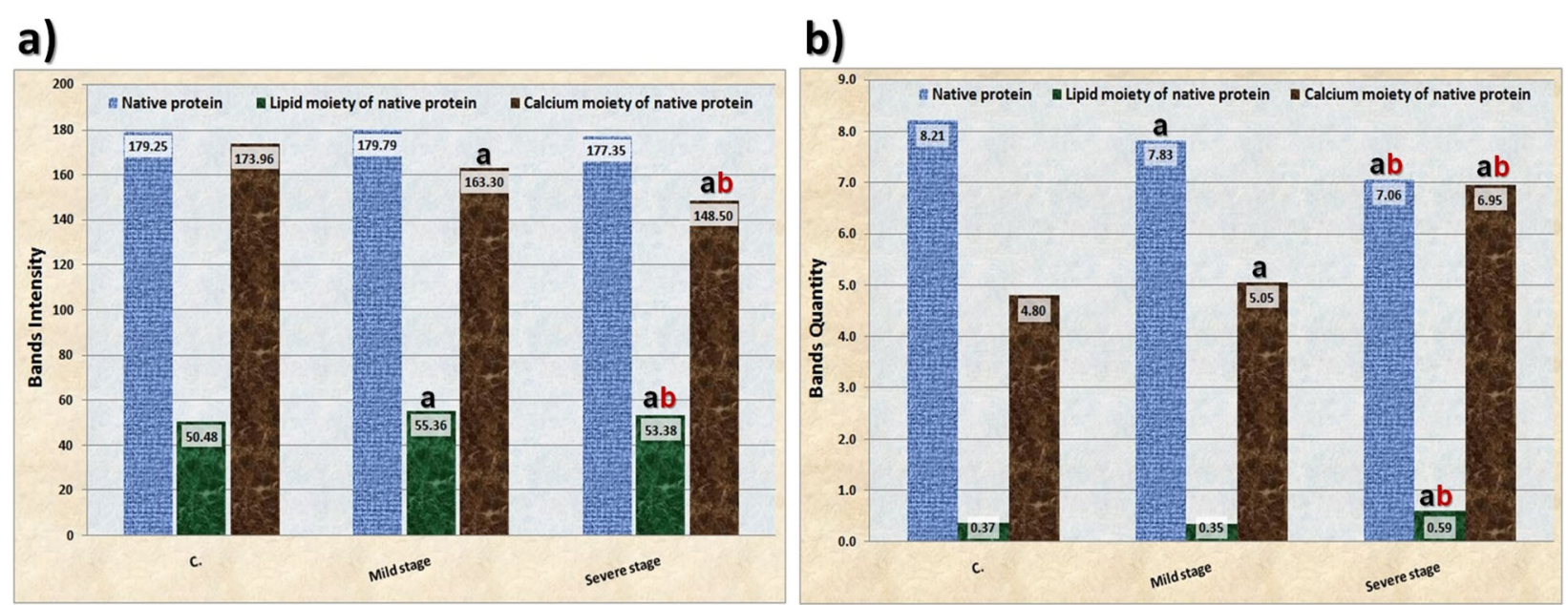

Fig. 2 Statistical comparison showing the differences in a) Intensities and b) Quantities of the total bands of electrophoretic native protein, lipid and calcium moieties of native proteins in asthmatic bronchitis patients at mild and severe stages as compared to control (healthy individuals). ${ }^{2}$ Significant difference as compared to control $(P<0.05)$, ${ }^{b}$ Significant difference as compared to patients at mild stage $(P<0.05)$

From dendogram and SI\% calculations, it was found that number and arrangement of CAT bands at mild and severe stages are similar to those of control by 95.2 and $35.4 \%$, respectively. In addition, the mild and severe stages of the disease are physiologically similar by $32.6 \%$.

As presented graphically in Fig. 3b, it was found that 5 normal types of POX isoenzyme were identified at Rfs $0.059,0.273,0.393$, and 0.697 (B\% 21.88, 19.72, 18.33, 21.77 , and 18.30 , respectively). There is only one common band identified at $\operatorname{Rf} 0.393$ (B\% 21.77). Three normal bands disappeared in asthmatic bronchitis patients at both mild and severe stages but it was noticed that one characteristic band was identified in patients at mild stage at Rf 0.866 (B\% 29.79). Moreover, one characteristic band identified in patients at severe stage at $\mathrm{Rf}$ 0.181 (B\% 32.74).

The dendogram and SI\% values showed that number and arrangement of bands of POX isoenzyme in the patients at mild stage is similar to those of control by $40.1 \%$. Moreover, the disease at severe stage is physiologically similar to control by $50.5 \%$. Furthermore, the

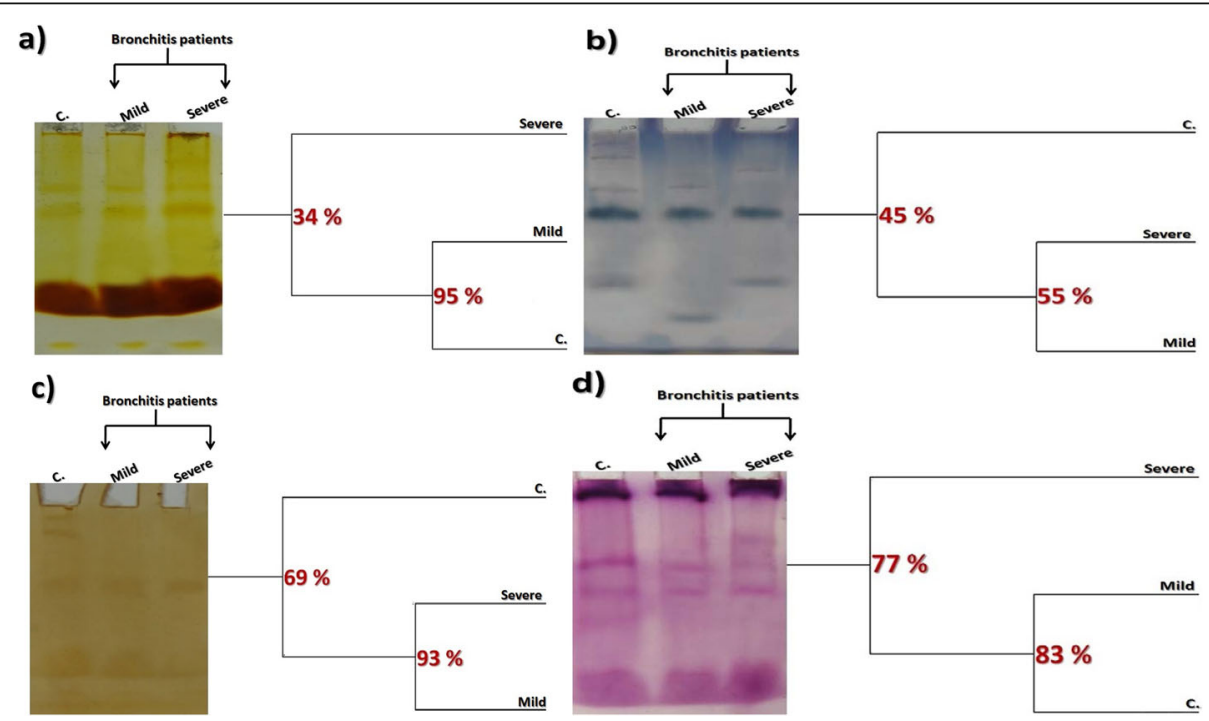

Fig. 3 Electrophoretic isoenzymes patterns showing the physiological variations in bands number, arrangement and similarity percent (SI\%) in a) Catalase (CAT,

b) Peroxidase (POX), c) a-Esterase (a-EST) and d) $\beta$-Esterase ( $\beta$-EST) in asthmatic bronchitis patients at mild and sever stages as compared to control (healthy individuals) 
mild and severe stages of the disease are physiologically similar by $54.9 \%$.

Data illustrated graphically in Fig. 3c showed that $\alpha$ EST isoenzyme was represented by 6 normal types identified at Rfs $0.05,0.137,0.37,0.783,0.893$, and 0.97 (B\% $16.94,16.29,16.38,16.33,17.02$, and 17.04, respectively). Four common $\alpha$-EST types were identified at Rfs 0.37 , 0.783, 0.893, and 0.97 (B\% 16.38, 16.33, 17.02 and 17.04, respectively). It was observed that 2 normal $\alpha$-EST types were disappeared in patients at both stages without existence of abnormal ones.

Values of the calculated SI\% postulated that number and arrangement of bands in $\alpha$-EST isoenzymes in the disease at mild stage is similar to those of control by $67.9 \%$. Moreover, the disease at severe stage is physiologically similar to control by $69.6 \%$. Patients at mild and severe stages are physiologically similar by $93.3 \%$.

As revealed in Fig. 3d, it was stated that $\beta$-EST isoenzyme was represented by 5 normal types identified at Rfs $0.05,0.343,0.466,0.581$, and 0.881 (B\% 25.84, 18.53, $18.40,17.44$, and 19.81 , respectively). Four common $\beta$ EST types were identified at Rfs $0.05,0.343,0.466$, and 0.881 (B\% 25.84, 18.53, 18.40, and 19.81, respectively). In patients at severe stage, one normal $\beta$-EST type was disappeared with appearance of one characteristic band at Rf 0.256 (B\% 17.04). As regards to patients at mild stage, one normal $\beta$-EST type was disappeared without appearance of abnormal one.

As revealed from the dendogram and SI\% values, it was found that number and arrangement of bands in $\beta$ EST isoenzyme in the disease at mild stage is similar to those of control by $83.1 \%$. Moreover, the disease at severe stage is physiologically similar to control by $73.1 \%$. Patients at mild and severe stages are physiologically similar by $80.5 \%$.

As presented graphically in Fig. 4a, it was found that intensities of CAT and $\beta$-EST bands decreased significantly $(P<0.05)$ in asthmatic bronchitis patients at mild stage. No statistical difference was noticed in intensities of POX and $\alpha$-EST bands in that disease stage. In patients at severe stage, it was stated that intensities of CAT and $\alpha$-EST bands increased significantly $(P<0.05)$ as compared to control and patients at mild stage. No statistical differences were noticed in intensities of POX and $\beta$-EST bands in that stage as compared to control and patients at mild stage.

As regards to quantities of isoenzymes bands (Fig. 4b), it was found that quantities of POX bands increased significantly $(P<0.05)$ in patients at mild stage associated with lowering quantities of $\beta$-EST bands significantly $(P<0.05)$ as compared to healthy individuals. No statistical differences were noticed in quantities of CAT and $\alpha$-EST bands in patients at that stage. In patients at severe stage, quantities of CAT, $\alpha$-EST and $\beta$-EST bands lowered significantly $(P<0.05)$ with respect to control. While with respect to patients at mild stage, quantities of CAT, POX and $\alpha$-EST bands decreased significantly $(P<0.05)$ associated with elevation of $\beta$-EST bands quantities.

Data compiled in Table 3 showed the positive and negative correlations among intensities and quantities of the native electrophoretic patterns in asthmatic
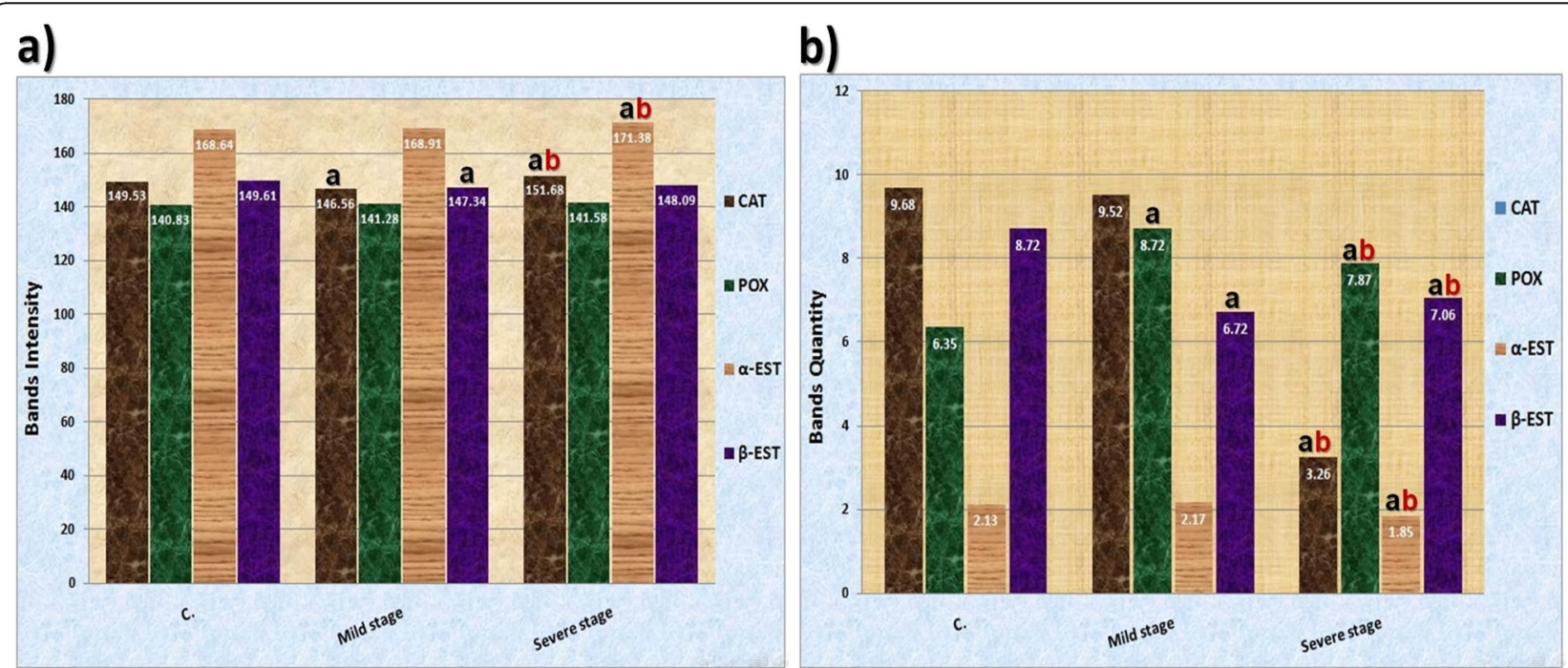

Fig. 4 Statistical comparison showing the differences in a) Intensities and b) Quantities of the total bands of electrophoretic catalase, peroxidase, $a$ - and $\beta$-esterases in asthmatic bronchitis patients at mild and severe stages as compared to control (healthy individuals). ${ }^{a}$ Significant difference as compared to control $(P<0.05)$, 'b Significant difference as compared to patients at mild stage $(P<0.05)$ 
bronchitis patients at mild and severe stages before and after receiving treatment.

\section{Discussion}

As suggested by Dhahir and Noaman (2017), it was necessary to measure liver enzymes (AST and ALT) and electrolytes in case of pulmonary diseases. These enzymes exhibit their functions by catalyzing transfer of the amino group converting aspartate and alanine into oxaloacetate and pyruvate, respectively. Moreover, the electrolytes play a major role in regulating the body fluids, maintaining normal acid base balance, blood clotting, muscles contractions and nerve conduction. Consequently, the disturbances in the electrolytes lead to hepatic disease, coronary heart disease, renal failure and endocrine disorders (Jay et al., 2000; John, 2007).

During the present study, it was found that the liver enzymes were significantly $(P<0.05)$ elevated in asthmatic bronchitis patients at mild and severe stages with respect to control. This might due to release of high level of the cellular oxidative radicals as supported by findings of Wannamethee and Shaper (Wannamethee and Shaper, 2010), although some of the recent studies argued that the factors affecting pulmonary tissue does not cause damage to hepatocytes directly (Nagao and Sata, 2010).

Markers of kidney functions elevated significantly in asthmatic bronchitis patients. This was in agreement with Huang et al. (2014) who reported that the patients with asthmatic bronchitis may have increased risk of developing chronic kidney disease. This might refer to severe retention of salt and water, reduction in renal blood flow, and the abnormalities in glomerular filtration rate and of water handling that occur in association to the chronic asthmatic bronchitis (Daggett, 1977; Anand et al., 1992).

Arterial blood gases are considered as one of the first critical tests because it is an extremely useful to assess the oxygenation, $\mathrm{pH}$, and $\mathrm{PCO}_{2}$ giving information about status of oxygenation and ventilation which disturbed seriously in case of severe asthmatic bronchitis (Padmavathi et al., 2013). In the present study, no significant differences recorded in parameters of blood gases in the asthmatic bronchitis patients. These results were supported by findings of Illhan et al. (2016) who documented that there were no significant differences the arterial blood gases in the asthmatic bronchitis. Therefore, the blood gases were not found useful tool for predicting mortality in that patients.

Sodium and potassium assists for maintaining the balance between the body electrolytes and water (Nguen and Kurtz, 2004). The current study showed that there were no significant changes in serum $\mathrm{Na}^{+}, \mathrm{K}^{+}, \mathrm{Mg}^{2+}$ and $\mathrm{P}^{3+}$ in the asthmatic bronchitis patients. This was in accordance with the concept suggested by Al-harbi (2012) who postulated that there were no significant differences in these measurements, since people consume enough salt in diet.

Regarding $\mathrm{Ca}^{2+}$ level, it was found that $\mathrm{Ca}^{2+}$ decreased significantly in asthmatic bronchitis patients at severe stage when compared to healthy group and patients at mild stage. This might be attributed to alterations in the

Table 3 Significant correlations among intensities and quantities of the native electrophoretic patterns in asthmatic bronchitis patients at mild and severe stages before and after receiving treatment

\begin{tabular}{|c|c|c|c|c|c|c|c|c|c|c|c|c|c|c|c|}
\hline & & \multicolumn{2}{|c|}{ Protein } & \multicolumn{2}{|c|}{ Lipid Moiety } & \multicolumn{2}{|c|}{ Calcium Moiety } & \multicolumn{2}{|c|}{ CAT } & \multicolumn{2}{|c|}{ Pox } & \multicolumn{2}{|c|}{$\alpha$-EST } & \multicolumn{2}{|c|}{$\beta$-EST } \\
\hline & & Int & Qty & Int & Qty & Int & Qty & Int & Qty & Int & Qty & Int & Qty & Int & Qty \\
\hline \multirow{2}{*}{ Protein } & Int & - & & & $-0.038^{*}$ & & & $-0.004^{* *}$ & $0.015^{*}$ & & & & & & \\
\hline & Qty & & - & & $-0.000^{* *}$ & $0.000^{* *}$ & $-0.000^{* *}$ & $-0.001^{* *}$ & & & $-0.000^{* *}$ & $-0.000^{* *}$ & $0.000^{* *}$ & $0.000^{* *}$ & $0.000^{* *}$ \\
\hline \multirow{2}{*}{ Lipid Moiety } & Int & & & - & & $-0.000^{* *}$ & $0.029^{*}$ & $-0.020^{*}$ & & & $0.000^{* *}$ & & & $-0.001^{* \prime}$ & $-0.000^{* *}$ \\
\hline & Qty & $-0.038^{*}$ & $-0.000^{* *}$ & & - & $0.000^{* *}$ & $0.000^{* *}$ & $0.000^{* *}$ & $-0.000^{* *}$ & $0.020^{*}$ & & $0.000^{* *}$ & $-0.000^{* *}$ & & $-0.005^{* *}$ \\
\hline \multirow{2}{*}{ Calcium Moiety } & Int & & $0.000^{* *}$ & $-0.000^{* *}$ & $0.000^{* *}$ & - & $-0.000^{* *}$ & $-0.020^{*}$ & $0.000^{* *}$ & & $-0.000^{* *}$ & $-0.000^{* *}$ & $0.000^{* *}$ & $0.000^{* *}$ & $0.000^{* *}$ \\
\hline & Qty & & $-0.000^{* *}$ & $0.029^{*}$ & $0.000^{* *}$ & $-0.000^{* *}$ & - & $-0.000^{* *}$ & $0.000^{* *}$ & & $0.004^{* *}$ & $0.000^{* *}$ & $-0.000^{* *}$ & $-0.024^{*}$ & $-0.000^{* *}$ \\
\hline \multirow{2}{*}{ CAT } & Int & $-0.004^{* *}$ & $-0.001^{\prime *}$ & $-0.020^{\circ}$ & $0.000^{* *}$ & $-0.020^{*}$ & $-0.000^{* *}$ & - & $-0.000^{* *}$ & & $-0.036^{*}$ & $0.002^{* *}$ & $-0.003^{* *}$ & & \\
\hline & Qty & $0.015^{*}$ & & & $-0.000^{* *}$ & $0.000^{* *}$ & $0.000^{* *}$ & $-0.000^{* *}$ & - & & $-0.019^{*}$ & $-0.000^{* *}$ & $0.000^{* *}$ & & $0.000^{* *}$ \\
\hline \multirow{2}{*}{ POX } & Int & & & & $0.020^{*}$ & & & & & - & & $0.002^{+*}$ & & $0.005^{*+}$ & \\
\hline & Qty & & $-0.000^{* *}$ & $0.000^{* *}$ & & $-0.000^{* *}$ & $0.004^{* *}$ & $-0.036^{*}$ & $-0.019^{*}$ & & - & $0.007^{* *}$ & & $-0.000^{* *}$ & $-0.000^{* *}$ \\
\hline \multirow{2}{*}{$\alpha$-EST } & Int & & $-0.000^{* *}$ & & $0.000^{* *}$ & $-0.000^{* *}$ & $0.000^{* *}$ & $0.002^{* *}$ & $-0.000^{* *}$ & $0.002^{* *}$ & $0.007^{* *}$ & - & $-0.000^{* *}$ & & $-0.000^{* *}$ \\
\hline & Qty & & $0.000^{* *}$ & & $-0.000^{* *}$ & $0.000^{* *}$ & $-0.000^{* *}$ & $-0.003^{* *}$ & $0.000^{* *}$ & & & $-0.000^{* *}$ & - & & $0.024^{*}$ \\
\hline \multirow{2}{*}{$\beta$-EST } & Int & & $0.000^{* *}$ & $-0.001^{* *}$ & & $0.000^{* *}$ & $-0.024^{*}$ & & & $0.005^{* *}$ & $-0.000^{* *}$ & & & & $0.000^{* * *}$ \\
\hline & Qty & & $0.000^{* *}$ & $-0.000^{* *}$ & $-0.005^{* *}$ & $0.000^{* *}$ & $-0.000^{* *}$ & & $0.000^{* *}$ & & $-0.000^{* *}$ & $-0.000^{* *}$ & $0.024^{*}$ & $0.000^{* *}$ & - \\
\hline
\end{tabular}

* Significant correlation at $\mathrm{P}<0.05 ;{ }^{* *}$ High significant correlation at $\mathrm{P}<0.01$

Yellow cell indicates non-significant correlation, Orange cell indicates negative correlation, Green cell indicates positive correlation 
mechanisms that regulate the electrolyte levels inside and outside the cells in response to this deleterious factor leading to loss of the large amounts of $\mathrm{Ca}^{2+}$ in the urine. Moreover, this factor might affect the parathyroid gland which is responsible for regulating the $\mathrm{Ca}^{2+}$ level in the serum. This exhibited adverse effect on the body and bone metabolism due to reduction of the $\mathrm{Ca}^{2+} \mathrm{ab}-$ sorption and the bone density (Jorde et al., 2005).

Spirometry plays an important role in evaluation of asthma, including responsiveness to bronchodilators (Backman et al., 1997). The treatment decreased the bronchial hyper-responsiveness and inflammation to prevent further deterioration in the pulmonary indexes (FEV1, FVC, FEV1/FVC \%, and MEP) which are considered important parameters for asthma diagnosis and follow-up (Eden et al., 2006; Ciprandi et al., 2012; Guarnieri, 2017; Segal and Martinez, 2018). During the present study, it was found that the pulmonary indexes in patients with asthmatic bronchitis were higher after treatment than those before treatment. This was in agreement with Hou et al. (2018) who reported that these alterations might be attributed to the changes in polymorphism of vitamin $\mathrm{D}$ receptor gene which is negatively correlated with severity of asthma.

Proteins are the macromolecules that act as key players inside the cells. They facilitate transporting hormones, vitamins, minerals, lipids and other materials in addition to their effective role for maintaining the delicate blood acid-alkaline balance and balance the osmotic pressure of the blood and tissue (Ali et al., 2006). They circulate to the lungs through the blood stream for protecting that tissue from damage induced by elastases which degrade components of the extracellular matrix (Lewis, 2012). As a result of exposure of the lungs to inflammatory stimuli, elastases expressed severely accelerating asthma and hence lesions of the lung tissue (Crystal, 1990). The serum proteins are susceptible to be oxidized depending on the relative content of oxidationsensitive amino acid residues. Not all proteins are expressed at all times; their expression related to the cellular phenotype and it depends on physiological and environmental factors (Östman et al., 2011).

Protein pattern is a useful tool for diseases diagnosis and the individual serum proteins vary in their physiological functions enable the discovery of diseases biomarkers (O'Connell et al., 2005). The PAGE was used for separation and identifying of different proteins depending on charge, size and shape of protein molecules. Each native band is consisting of group of individual proteins with independent metabolic properties ( $\mathrm{O}^{\prime} \mathrm{Con}$ nell et al., 2005; Shah et al., 2010). This technique was used during the current study to show the adverse effect of asthmatic bronchitis on the different intracellular macromolecules inside the cells. It was noticed that severe alterations detected electrophoretically in number and arrangement of the native proteins. This may refer to the free radicals which cause defect in DNA proteins through the direct modifications in side chains of the amino acids. It was found previously that the amino acids which contain aromatic side chain groups are the most sensitive to the free radicals attack, and these amino acids form carbonyl products irreversibly during the oxidation reaction (Shringarpure et al., 2003; Srinivasan et al., 2006).

Lipoproteins exhibit effective role in carrying all types of lipids, but in different proportions. The serum lipoproteins are susceptible to be oxidized by hydroxyl radicals (Boldyrev et al., 1997). Density of the lipoprotein is directly proportional to the protein content and inversely proportional to the lipid content (Bass et al., 1993). For this reason, the alterations in lipoprotein pattern may refer to the changes in the protein portion.

Calcium moieties of native protein are low molecular weight acidic proteins. They exert inhibitory effect on formation of hydroxyapatite and, consequently, lead to alteration in the mineralization process (Hunter et al., 1996). The alterations in this native pattern result in abnormal mineralization of tissues (Luo et al., 1997). Therefore, the alterations in this native pattern might be correlated to the decline in $\mathrm{Ca}^{2+}$ level.

The SI\% is inversely proportional to the genetic variation. When the SI\% value between the abnormal group and the healthy group recorded low values, this indicates to the adverse effect of these substances and the differences in number and arrangement of the protein bands (Abdalla et al., 2015; Sharada et al., 2015). The electrophoretic alterations can be represented qualitatively through disappearance of normal bands and appearance of abnormal ones. Otherwise, the alterations may occur at the quantitative level through remaining the normal bands but with changing the band quantity. The SI\% is only correlated to the qualitative alterations (Aboulthana et al., 2016).

Due to data of the electrophoretic study, it was found that there were severe alterations in CAT and POX patterns in sera of asthmatic bronchitis patients. This might be occurred due to effect of the free radicals which were able to cause several molecular alterations involving directly in accumulation of genetic changes and depletion of antioxidant enzymes (Conti, 1997). Consequently, this leads to changes in the fractional activity of different isoenzymes correlated with variations in rates of protein expression secondary to DNA damage and hence affecting the isoenzymes (El-Zayat, 2007).

Activity of EST-like albumin used as prognostic markers for various diseases (Thangthaeng et al., 2011). It is expressed as several molecular forms that can be distinguished by their molecular weights and 
hydrodynamic properties (Massoulié et al., 1993). It can be visualized by substrate staining with using $\alpha$ - and $\beta$ naphthyl acetate in the presence of Fast Blue RR salt as a dye coupler (Ahmad et al., 2012). During the current study, it was found that the EST pattern was altered qualitatively and quantitatively. This might occur as a result of expression of markers of oxidative stress (Abulyazid et al., 2017; Gangadharan et al., 2007).

The previous studies confirmed that the differences in electrophoretic isoenzymes might be attributable to generation of the free radicals which cause oxidation at level of the nucleic acids. This leads to the formation of various molecular lesions including oxidized bases (purines and pyrimidines), abasic sites (apurinic/apyrimidinic sites) and DNA single- and/or double-strand breaks. Guanine is the most DNA base which is susceptible to be oxidized (Neeley and Essigmann, 2006). Hydroxyl radicals react with pyrimidines (thymine and cytosine) at positions 5 or 6 of the ring producing several lesions (Fujii et al., 2005). If there were no alterations in protein expression, enzymatic activity was not altered (Djordjevic et al., 2010). Moreover, the alterations in the electrophoretic isoenzymes may be attributed to effect of the free radicals which are directly targeting on the nucleic acids (DNA and RNA) responsible for biosynthesis of these enzymes (Javed et al., 2014).

\section{Conclusion}

The study concluded that liver and kidney functions were elevated in asthmatic bronchitis patients. No significant differences noticed in the pulmonary indices and arterial blood gases and most of electrolytes $\left(\mathrm{Na}^{+}\right.$, $\mathrm{K}^{+}, \mathrm{Mg}^{2+}$ and $\mathrm{P}^{3+}$ ) in all patients. Moreover, $\mathrm{Ca}^{2+}$ is the only electrolyte decreased at severe stage of the disease.

The native electrophoretic patterns showed that the disease at mild and severe stages were identical to control by 54.5 and $75.6 \%$ (protein), 73.1 and $41.6 \%$ (lipid moiety), 66.4 and 30.6\% (calcium moiety), respectively. As regards electrophoretic isoenzymes, it was found that the disease at mild and severe stages were similar to control by 95.2 and 35.4\% (CAT), 40.1 and 50.5\% (POX), 67.9 and $69.6 \%$ ( $\alpha$-EST), 83.1 and $73.1 \%$ $(\beta$-EST), respectively.

\section{Abbreviations}

ALT: Alanine Aminotransferase; AST: Aspartate Aminotransferase; B\%: Band Percent; CAT: Catalase; COPD: Chronic Obstructive Pulmonary Disease; FEV1: Forced Expiratory Volume in 1 Second; FVC: Forced Vital Capacity; HB: Hemoglobin; MEP: Maximal Expiratory Pressure; Mwts: Molecular Weights; One-way ANOVA: One-Way Analysis of Variance; PAGE: Polyacrylamide Gel Electrophoresis; PLT: Platelets; POX: Peroxidase; Rf: Relative Mobility; SBB: Sudan Black B; SE: Standard Error; SI\%: Similarity Index; WBCs: White Blood Cells; $\boldsymbol{a}$-EST: $\boldsymbol{a}$-Esterase; $\beta$-EST: $\beta$-Esterase

\section{Authors' contributions}

All authors collected the theoretical details from the previous studies and draft the manuscript. Wael Mahmoud Aboulthana proposed the research concept and designed the experimental plan. He performed laboratory measurements, statistical analysis and wrote the first draft of the manuscript. Marwa Darwish, Mohab Halim and Hatim El-Baz contributed to experimental design and participated in laboratory analyses. Osama Ahmed was involved in patient recruitment, blood samples collection and data acquisition. He was responsible for the disease diagnosis, collecting clinical data sheets and selecting the cases to be under this study according to the inclusion and exclusion criteria. Also, he was concerned with determining the disease stage (mild and severe). All the authors conceived and designated the study and critically reviewed the manuscript. They have accepted responsibility for the entire content of this submitted manuscript and approved submission.

\section{Funding}

The authors were not financially supported and they were responsible for cost of the analysis and materials consumed during the study.

\section{Availability of data and materials}

The authors are ready to send the detailed scientific materials if it is useful for readings.

\section{Ethics approval and consent to participate}

All procedures carried out in studies involving human participants were in accordance with the ethical standards of Institutional Human Ethical Committee of National Research Centre, Dokki, Giza, Egypt, and with the 1964 Helsinki Declaration and its later amendments or comparable ethical standards.

Consent for publication

Not applicable

\section{Competing interests}

The authors have no declared conflicts of interests. They are responsible for content and writing of this article.

\section{Author details}

${ }^{1}$ Biochemistry Department, Genetic Engineering and Biotechnology Research Division, National Research Centre, Dokki, Giza P.O. 12622 Egypt. ${ }^{2}$ Chemistry Department (Biochemistry Branch), Faculty of Science, Suez University, Suez P.O. 43518 Egypt. ${ }^{3}$ College of Applied Medical Sciences, Shaqraa University, Kowaiyia, Kingdom of Saudi Arabia. ${ }^{4}$ Clinical Biochemistry Department, Faculty of Medicine, University of Jeddah, Jeddah, Kingdom of Saudi Arabia. ${ }^{5}$ Department of Internal Medicine, Medical Research Division, National Research Centre, Dokki, Giza P.O. 12622 Egypt.

Received: 11 November 2019 Accepted: 27 April 2020

Published online: 01 June 2020

\section{References}

Abd Elhalim SA, Sharada HM, Abulyazid I, Aboulthana WM, Abd Elhalim ST (2017) Ameliorative effect of carob pods extract (Ceratonia siliqua L.) against cyclophosphamide induced alterations in bone marrow and spleen of rats. Journal of Applied Pharmaceutical Science 7(10):168-181

Abdalla MS, Sharada HM, Abulyazid I, Abd El Kader MA, Kamel WM (2015) Ameliorative effect of salicin against gamma irradiation induced electrophoretic changes in brain tissue in male rats. UK Journal of Pharmaceutical and Biosciences 3(2):29-41

Aboulthana WM, Ismael M, Farghaly HS (2016) Assessment of mutagenicity induced by toxic factors affecting ovarian tissue in rats by electrophoresis and molecular dynamic modeling. International Journal of Current Pharmaceutical Review and Research 7(6):347-359

Abulyazid I, Abd Elhalim SA, Sharada HM, Aboulthana WM, Abd Elhalim STA (2017) Hepatoprotective Effect of Carob Pods Extract (Ceratonia siliqua L.) against Cyclophosphamide Induced Alterations in Rats. International Journal of Current Pharmaceutical Review and Research 8(2):149-162

Ahmad A, Maheshwari V, Ahmad A, Saleem R, Ahmad R (2012) Observation of esterase-like-albumin activity during $\mathrm{N}^{\prime}$-nitrosodimethyl amine induced hepatic fibrosis in a mammalian model. Maced J Med Sci 5(1):55-61

Al-harbi W (2012) Electrolytes changes in cigarette smoking male students. Pakistan Journal of Pharmacology 29:33-38 
Ali SA, El-Rigal NS, Rizk MZ (2006) Nutritional supplementation with Ailanthus altissimia and Ziziphus spina Christi to compensate for some metabolic disorders in Schistosoma mansoni infected mice. Pak J Biol Sci 9(9):1700-1706

Anand IS, Chandrashekhar Y, Ferrari R, Sarma R, Guleria R, Jindal SK, Wahi PL, Poole-Wilson PA, Harris P (1992) Pathogenesis of congestive state in chronic obstructive pulmonary disease. Studies of body water and sodium, renal function, hemodynamics, and plasma hormones during edema and after recovery. Circulation 86(1):12-21

Backman KS, Greenberger PA, Patterson R (1997) Airways obstruction in patients with long-term asthma consistent with "irreversible asthma". Chest 112:1234-1240

Bass KM, Newschaffer C, Klag MJ, Bush TL (1993) Plasma lipoprotein levels as predictors of cardiovascular death in women. Arch Intern Med 153(19):2209-2216

Blasi F, Tarsia P, Mantero M, Morlacchi LC, Piffer F (2013) Cefditoren versus levofloxacin in patients with exacerbations of chronic bronchitis: Serum inflammatory biomarkers, clinical efficacy, and microbiological eradication. Ther Clin Risk Manag 9:55-64

Boldyrev AA, Stvolinsky SL, Tyulina OV, Koshelev VB, Hori N, Carpenter DO (1997) Biochemical and physiological evidence that carnosine is an endogenous neuroprotector against free radicals. Cell Mol Neurobiol 17(2):259-271

Bradford MM (1976) A rapid and sensitive method for the quantitation of microgram quantities of protein utilizing the principle of protein-dye binding. Anal Biochem 72(1-2):248-254

Ciprandi G, Capasso M, Tosca M, Salpietro C, Salpietro A, Marseglia G, La Rosa M (2012) Forced expiratory flow at $25-75 \%$ value $<65 \%$ of predicted should be considered abnormal: a real-world, cross-sectional study. Allergy Asthma Proc 33(1):e5-e8

Conti CJ (1997) Mechanisms of tumor progression. In: Sipes IG, McQueen CA, Gandolfi AJ (eds) Comprehensive Toxicology 12, pp 383-400

Crystal RG (1990) Alpha 1-antitrypsin deficiency, emphysema, and liver disease. Genetic basis and strategies for therapy. J Clin Invest 85:1343-1352

Daggett P (1977) An investigation of renal function in chronic bronchitis. Postgrad Med J 53(615):24-27

Darwesh OM, Moawad H, Barakat OS, Abd El-Rahim WM (2015) Bioremediation of Textile Reactive Blue Azo Dye Residues using Nanobiotechnology Approaches. Research Journal of Pharmaceutical, Biological and Chemical Sciences 6(1):1202-1211

Dhahir NK, Noaman AA (2017) Study effect of cigarette smoking on the liver functions and electrolytes. Iraqi Journal of Science 58(1B):211-215

Djordjevic J, Djordjevic A, Adzic M, Niciforovic A, Radojcic MB (2010) Chronic stress differentially affects antioxidant enzymes and modifies the acute stress response in liver of wistar rats. Physiol Res 59(5):729-736

Eden E (2010) Asthma and COPD in alpha-1 antitrypsin deficiency. Evidence for the Dutch hypothesis. Int J Chron Obstruc Pulmon Dis 7:366-374

Eden E, Strange C, Holladay B, Xie L (2006) Asthma and allergy in alpha-1 antitrypsin deficiency. Respir Med 100:1384-1391

El-Zayat EM (2007) Isoenzyme pattern and activity in oxidative stress-induced hepatocarcinogenesis: the protective role of selenium and vitamin $\mathrm{E}$. Research Journal of Medicine and Medical Sciences 2(2):62-71

Freire ID, Abreu E, Silva FA, Araújo MA (2008) Comparison among pulmonary function test results, the Shwachman-Kulczycki score and the Brasfield score in patients with cystic fibrosis. J Bras Pneumol 34:280-287

Fujii J, luchi Y, Okada F (2005) Fundamental roles of reactive oxygen species and protective mechanisms in the female reproductive system. Reprod Biol Endocrinol 3:43

Gangadharan B, Antrobus R, Dwek RA, Zitzmann N (2007) Novel serum biomarker candidates for liver fibrosis in hepatitis C patients. Clin Chem 53(10):1792-1799

Griffith DE, Garcia JG (1988) Asthmatic bronchitis. Semin Respir Infect 3(1):27-39

Guarnieri G (2017) Diagnostic approach to occupational allergic respiratory diseases. G Ital Med Lav Ergon 39(3):178-181

Hames BD (1990) One-dimensional polyacrylamide gel electrophoresis. In: Hames BD, Rickwood D (eds) Gel electrophoresis of proteins, 2nd edn. Oxford University Press, New York, pp 1-147

Han RF, Li HY, Wang JW, Cong XJ (2016) Study on clinical effect and immunologic mechanism of infants capillary bronchitis secondary bronchial asthma treated with bacterial lysates Broncho-Vaxom. Eur Rev Med Pharmacol Sci 20:2151-2155

Hou C, Zhu X, Chang X (2018) Correlation of vitamin D receptor with bronchial asthma in children. Experimental and Therapeutic Medicine 15:2773-2776

Huang HL, Ho SY, Li CH, Chu FY, Ciou LP, Lee HC, Chen WL, Tzeng NS (2014) Bronchial asthma is associated with increased risk of chronic kidney disease. BMC Pulm Med 14:80
Hunter GK, Hauschka PV, Poole AR, Rosenberg LC, Goldberg HA (1996) Nucleation and inhibition of hydroxyapatite formation by mineralized tissue proteins. Biochem J 317(Pt 1):59-64

Ilthan S, Günay R, Özkan S, Güvenç TS, Yurtsever N (2016) Arterial blood gas analysis in chronic obstructive pulmonary disease patients undergoing coronary artery bypass surgery. Turk Thorac J 17(3):93-99

Javed A, Ashwini LS, Muralidhar TS, Sagar S, Medam SK (2014) Effect of quercetin on cyclophosphamide induced biochemical profiles in rat liver. International Journal of Research Studies in Biosciences (IJRSB) 2(10):40-46

Jay NC, Peter RK, Paul KW, Prisant M (2000) A contemporary review by the national council on potassium in clinical practice. Arch Intern Med Journal 160:2429-2436

John AK (2007) Disorders of acid- base balance. Crit Care Med Journal 35:26302636

Jorde R, Salehl F, Figenschau Y, Kamycheva E, Haug E, Sundsfjord J (2005) Serum parathyroid hormone (PTH) levels in smokers and nonsmokers. Eur Journal of Endocrinol 152:39-45

Lewis EC (2012) Expanding the clinical indications for alpha(1)-antitrypsin therapy. Mol Med 18:957-970

Luo G, Ducy P, McKee MD, Pinero GJ, Loyer E, Behringer RR, Karsenty G (1997) Spontaneous calcification of arteries and cartilage in mice lacking matrix GLA protein. Nature 386(6620):78-81

Massoulié J, Pezzementi L, Bon S, Krejci E, Vallette F-M (1993) Molecular and cellular biology of cholinesterases. Prog Neurobio 141(1):31-91

Molyneux E, Riordan FA, Walsh A (2006) Acute bacterial meningitis in children presenting to the Royal Liver pool Children's Hospital, Liverpool, UK and the Queen Elizabeth Central Hospital in Blantyre, Malawi: A world of difference. Ann Trop Paediatr 26:29-37

Nagao Y, Sata M (2010) Serum albumin and mortality risk in a hyper endemic area of HCV infection in Japan. Virol Journal 7:375

Nahori MA, Lagranderie M, Lefort J, Thouron F, Joseph D, Winter N, Gicquel B, Lapa e Silva JR, Vargaftig BB (2001) Effects of Mycobacterium bovis BCG on the development of allergic inflammation and bronchial hyperresponsiveness in hyper-lgE BP2 mice vaccinated as newborns. Vaccine 19:1484-1495

Neeley WL, Essigmann JM (2006) Mechanisms of formation, genotoxicity, and mutation of guanine oxidation products. Chemical Research in Toxicology 19(4):491-505

Nguen MK, Kurtz I (2004) Determinants of plasma water sodium concentration as reflected in the Edelman equation: role of osmotic and Gibbs-Donnan equilibrium. Am Journal of Physiol Renal Physiol 286:828-837

O'Connell TX, Horite TJ, Kasravi B (2005) Understanding and interpreting serum protein electrophoresis. Am Fam Physician 71(1):105-112

Östman A, Frijhoff J, Sandin $\AA$, Böhmer F-D (2011) Regulation of protein tyrosine phosphatases by reversible oxidation. Journal of Biochemistry 150(4):345-356

Padmavathi K, Sumangali P, Subash YE (2013) Arterial blood gas analysis in acute and chronic bronchial asthma. Bulletin of Pharmaceutical and Medical Sciences (BOPAMS) 1(3):200-205

Rescigno A, Sanjust E, Montanari L, Sollai F, Soddu G, Rinaldi AC, Oliva S, Rinaldi A (1997) Detection of laccase, peroxidase and polyphenol oxidase on a single polyacrylamide gel electrophoresis. Anal Lett 30(12):2211-2220

Segal LN, Martinez FJ (2018) Chronic obstructive pulmonary disease subpopulations and phenotyping. J Allergy Clin Immunol 141(6):1961-1971

Shah PI, Bhatt PA, Patel PS, Ghori VL, Vaghela PD (2010) Study of Electrophoretic pattern in serum of Multiple Myeloma Patients. Int J Pharm \& Health Sci 1(2): 116-131

Sharada HM, Abdalla MS, Ibrahim IA, El Kader MA, Kamel WM (2015) Electrophoretic study of the antagonistic effect of salicin isolated from Egyptian willow leaves (Salix subserrata) against the effect of gamma irradiation in male rats. World Journal of Pharmacy and Pharmaceutical Sciences 4(05):1576-1602

Sherrill DL, Stein R, Halonen M, Holberg CJ, Wright A, Martinez FD (1999) Total serum lgE and its association with asthma symptoms and allergic sensitization among children. J Allergy Clin Immunol 104:28-36

Shringarpure R, Grune T, Mehlhase J, Davies KJA (2003) Ubiquitin conjugation is not required for the degradation of oxidized proteins by proteasome. The Journal of Biological Chemistry 278(1):311-318

Siciliano MJ, Shaw CR (1976) Separation and visualization of enzymes on gels. In: Smith I (ed) Chromatographic and Electrophoretic Techniques, Vol. 2, Zone Electrophoresis. Heinemann, London, p 185 
Srinivasan M, Sudheer AR, Pillai KR, Kumar PR, Sudhakaran PR, Menon VP (2006) Influence of ferulic acid on gamma-radiation induced DNA damage, lipid peroxidation And antioxidant status in primary culture of isolated rat hepatocytes. Toxicology Journal 228:249-258

Subramaniam HN, Chaubal KA (1990) Evaluation of intracellular lipids by standardized staining with a Sudan black B fraction. J Biochem Biophys Methods 21(1):9-16

Thangthaeng N, Sumien N, Forster MJ, Shah RA, Yan LJ (2011) Nongradient blue native gel analysis of serum proteins and in-gel detection of serum esterase activities. J Chromatogr A 879(5-6):386-394

Wannamethee SG, Shaper AG (2010) Cigarette smoking and serum liver enzymes: the Role of alcohol and inflammation. Ann Clin biochem Journal 47:321-326

Yadav M, Mittal K (2014) Effect of vitamin D supplementation on moderate to severe bronchial asthma. Indian J Pediatr 81:650-654

Yildiz Y, lgde M (2018) Evaluation of fractioned nitric oxide in chronic cough patients. Niger J Clin Pract 21(1):1-6

Zacharia SY, Kakati VS (2004) Characterisation of vitellogenin and vitellin of Fenneropenaeus merguiensis (De Man). Indian J Fish 51(3):255-263

\section{Publisher's Note}

Springer Nature remains neutral with regard to jurisdictional claims in published maps and institutional affiliations.

\section{Submit your manuscript to a SpringerOpen ${ }^{\circ}$ journal and benefit from:}

- Convenient online submission

- Rigorous peer review

- Open access: articles freely available online

- High visibility within the field

- Retaining the copyright to your article

Submit your next manuscript at $\boldsymbol{\nabla}$ springeropen.com 